The Economy of Nature: A Textbook in Basic Ecology. By Robert E. Ricklefs. Pp. v+455. (Chiron: Portland, Oregon, January 1976.) \$13.95. Methods in Plant Ecology. Edited by S. B. Chapman. Pp. viii +536 . (Blackwell Scientific: Oxford and London; Halsted: New York, 1976.) Cloth £15; paper $£ 9.75$.

Publishers of ecological textbooks would do well to consider Gause's principle of competitive exclusion. The cash in a student's pocket is a distinctly limited resource for which textbooks must compete; any new text, to be successful, must carve out a niche for itself in what is already a fairly saturated market. And in so doing it will inevitably displace other texts from that volume of literary hyperspace which they currently occupy. When considering a new text, one must therefore assess its competitive ability in the niche for which it has been designed.

Ricklef's new book is aimed at bridging the gap between the voluminous tests which seek to cover the whole gamut of ecological thought and the brief, sometimes superficial, introductory books. It has a broad coverage, following a very similar sequence to his previous book (Ecology, Thomas Nelson, 1973), but the text penetrates far less deeply than that volume. The style is light and readable and is uninterrupted by references to original papers. Some new illustrations, both verbal and pictorial, are introduced. although many of the old ones are retained. There is still a strong emphasis upon zoological and North American examples of the principles described.

Is there a niche for this textbook in the current market? I do not consider it a serious competitor with the variety of good texthooks currently available (including Ricklefs' Ecology and also Colinvaux, Introduction to Ecology, Wiley, 1973: Ecology, Krebs, Harper and Row, 1972: General Ecology, McNaughton and Wolf: Holt, Rinehart and Winston. 1973) for that portion of the 'resource' provided by British University students of biology. The low level of numerical treatment and the lack of references will prob- ably cause it to fail in this respect. It is not a textbook which generates a critical approach to the data and the conclusions presented; therefore, I do not think that it will displace any weightier text from this portion of its niche. It may appeal to the broaderbased groups of students possibly proceeding along paths encompassing humanities and environmental studies. Here its neglect of the numerical approach may be an asset. In this narrower niche, however, is the resource adequate to support a large population-that is how big is this specialised market? Where competition is weak it is often, although not invariably, due to low resource availability.

The second book, edited by Chapman, is making an overt bid to fill a specialised, relatively narrow niche in the textbook community, that of methodology in plant ecology. A wide range of disciplines, and methods within these disciplines is covered and, since each has a separate author, one might expect a degree of patchiness. The chapter on history of vegetation covers an enormous range of ideas, methods and techniques, but never in sufficient depth to provide an adequate laboratory manual. The key to pollen grains is inadequate, inaccurate and misleading. The description of vegetation is dealt with far too briefly, in the following chapter. Several good textbooks are now available on this subject and this short survey adds little new.
The chapter on production ecology is useful in that it explains very clearly and precisely the basis of productivity estimation and the various growth formulae that can be used. Once again it provides background information and methodological appraisal, but space (presumably) does not allow the detailed descriptions of techniques which would be required by neophytes.

Other topics covered include physiological ecology, soils, climatology, chemical analysis and data collection systems. In almost all cases the sheer pressure of space results in the abbreviation of technique description, although references to the literature are always numerous. The imposed brevity, however, does mean that the serious student of any specialised discipline is likely to look elsewhere for information, often to a text specifically on the required techniques. Competitive displacement is therefore an unlikely outcome of this publication. There remains the question of whether the gathering of all these varied techniques under a single cover might provide the book with a distinct niche of its own. I fear that this is unlikely; it may find its way into libraries or on to a few private shelves, but I cannot envisage its being bought by students; and this is where the real resource lies.

Peter Moore is a lecturer in the Department of Plant Science at King's College, University of London, UK.

\title{
Pollution control
}

The Estimation of Pollution Damage. (Studies in Environmental Pollution.) By P. J. W. Saunders. Pp. 126. (Manchester University: Manchester, April 1976.) $£ 6.95$.

No-ONE approves of pollution. Unfortunately, however, its control is not simple. A great deal of effort and money may be devoted to reducing the amount of some toxic substance in our environment, with little or no useful effect, because preliminary studies have not been made to find out what, if any, harmful effects the substance is really producing. Our resources are clearly insufficent to deal with every possible source of pollution, and it is therefore essential that we discover which are the greatest danger, and concentrate, first, on their control.

In this book Dr P. J. W. Saunders of the Natural Environment Research Council, and formerly of the Pollution Research Unit at Manchester University, sets out to show how the real, harmful effects of pollution may be measured, so that effective control measures may be planned. The book 